\title{
Survey and Monitoring of Chinese Citrus Fly (Bactrocera minax Enderlein) in Sweet Orange Orchards of Sindhuli, Nepal
}

\author{
Elina Gautam ${ }^{1}$, Arvind Srivastava ${ }^{1}$, Lalan Kumar Singh ${ }^{2}$, Shanta Karki ${ }^{3}$, Debraj Adhikari ${ }^{4}$, Umesh Acharya ${ }^{5}$ \\ and Resham Bahadur Thapa ${ }^{1}$ \\ ${ }^{1}$ Agriculture and Forestry University, Nepal \\ ${ }^{2}$ Agribusiness Promotion Support and Training Center, Dhanusha, Nepal \\ ${ }^{3}$ National Citrus Development Program, Kirtipur, Nepal \\ ${ }^{4}$ PMAMP, Sweet Orange Super Zone, Sindhuli, Nepal \\ ${ }^{5}$ National Citrus Research Program, Dhankuta, Nepal \\ Corresponding author's email: elinagautam@gmail.com
}

Received on: 14 July 2019, Revised on: 5 December 2019, Accepted on: 4 January 2020

\begin{abstract}
Chinese citrus fly, Bactrocera minax (Enderlein), is one of the most important pests of citrus. The pest is more problematic in the eastern part of the country, Nepal. Because of the difficulties associated with the control of this pest by chemical insecticides, farmers had experienced great losses in Sweet Orange. Therefore, a participatory field survey was conducted under farmer field conditions to assess losses and measure the efficacy of different local and recommended management options to address the problem of this pest. Study consisted of two major parts: monitoring of pest population and farmer's survey. For monitoring three orchards were selected located at different altitude i.e. 1200 masl, 1300 masl and 1400 masl. Great Fruit fly Bait (25\% protein hydrolysate and $0.1 \%$ abamectin) in McPhail traps were used for monitoring. Monitoring was done in every 7 days interval and lures were changed in every 15 days for the effectiveness. Only $18.3 \%$ farmers were using protein bait for the management of fruit fly. B. minax had peak population intensity at May and was found decreasing after June so the management practices should be adopted before June to prevent the loss by fruit fly. However, for best effective control attention for monitoring and management procedures has to take place throughout the life cycle of the insect
\end{abstract}

Keywords: : Bactrocera minax, Loss, Management, Monitoring, Protein hydrolysate

\section{Introduction}

Sweet orange (Citrus sinensis L. Osbeck) is one of the citrus fruit species belonging to the family Rutaceae. It is a hybrid between Citrus maxima (Pomelo) and Citrus reticulata (mandarin). Sweet orange (Junar), is the second important citrus fruit of Nepal after mandarin in terms of area and production (Adhikari et al., 2012). It is grown in 49 districts of Nepal, but the districts having significant amounts of production are Sindhuli, and
Ramechhap (Kaini, 2013).Despite of the well accepted value and importance of sweet orange production in terms of income and climatic suitability, the production of sweet orange is still low in Sindhuli. Among different causes of low production, such as traditional method of crop management, small scale production, legal and institutional constraints, lack of sufficient water, biotic and a biotic stress, fruit drop at early stage due to fruit fly infestation are the major problem of Sweet orange production in the district (DADO, 2010). 
Fruit fly is two winged insect of the family Tephritidae whose larva feed on vegetative parts or fruits. Their distribution is cosmopolitan covering tropical, subtropical and temperate regions (Agarwal \& Sueyoshi, 2005). In addition to the direct losses, fruit fly infestation can also result in serious losses in trade value and export opportunity, due to strict quarantine regulations imposed by most of the importing countries (Poudel \& Regmi, 2008) and (Adhikari, Dougound, Janner, \& Schaffner, 2016).In Nepal, Chinese citrus fly (Bactrocera minax) is reported to cause economic damage in the Sweet orange fruits in the eastern middle mountains. About 60 to $70 \%$ Sweet orange fruit drop has been reported in Dhankuta, Bhojpur and Khotang districts (NCRP, 2006). In Sindhuli last 3-4 year's fruit fly species mainly Bactrocera minax (Enderlein) was found to be problematic causing great economic loss during the time of harvesting (DADO, 2016) and (Adhikari \& Joshi, 2018). So it is very crucial to study the occurrence of the pest in order to formulate the strategies for its effective management (Adhikari et al., 2020). The major objective of the research was to study the occurrence of $B$. minax and its management practices adopted by farmers in sweet orange of Sindhuli district.

\section{Materials And Methods}

This study consists of two components: field survey and monitoring. Survey was carried out during the month of June, 2018 in Golanjor rural municipality (super zone area of sweet orange, Sindhuli).Similarly monitoring was done to study the abundance of fruit fly during the study period and to know the effectiveness of the lure used.

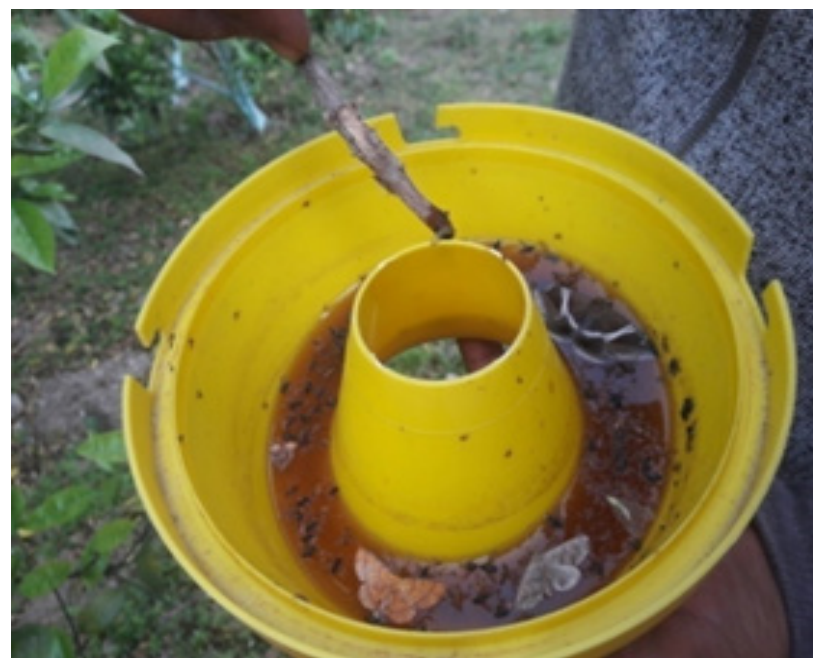

Figure 1: Installment of McPhail trap with protein bait in orchards of Sindhuli, 2018

\section{Field survey}

Golanjor rural municipality (ward no 4, 5, 6) and Kamalamai municipality (ward no 3) were selected purposively based on the area of production. Survey was conducted using semi- structured interview schedule. One hundred respondents from Golanjor rural municipality and 20 respondents from Kamalamai municipality (ward no 3) i.e. total 120 respondents were selected by using stratified random sampling One comprehensive Focus Group Discussion (FGD) was organized at the study area after completing the survey with help of the checklist to verify the result obtained from field survey. Secondary data were obtained from District Agriculture Development Office (DADO), annual reports, newsletters, bulletins and relevant articles, libraries and information office, Department of Agriculture, Ministry of Agriculture and Livestock Development (MoALD).

\section{Monitoring}

The site for the monitoring of fruit fly was Golanjor-05, Sindhuli, where orchards at three different locations1200, 1300 and 1400 masl were selected. At each location, one McPhail trap baited with $100 \mathrm{ml}$ of Great Fruit Fly bait (25\% protein hydrolysate with $0.1 \%$ abamectin). The traps were installed about $1.5 \mathrm{~m}$ above the ground and the lures were changed at every 15 days interval for more effective luring of the fruit fly.

The counting of the trapped fruit fly was done from 14th April to 30th June. The fruit flies were pinned for the species identification purpose and the species other than Bactrocera minax were discarded. The number of Bactrocera minax trapped in each trap was recorded in every count. All the data of monitoring were analyzed using SPSS Version 24 and Ms Excel.

\section{Results And Discussion}

\section{Respondents' awareness about Bactrocera minax (Enderlein)}

Majority of the respondents that is $81.7 \%$ had no knowledge about Bactrocera minax (Table 1). 


\begin{tabular}{|c|c|}
\hline \multicolumn{2}{|c|}{ Table 1. Respondents' awareness about Bactrocera minax (Enderlein) } \\
\hline Response & Frequency \\
\hline Yes & $22(18.3)$ \\
\hline No & $98(81.7)$ \\
\hline Total & $120(100)$ \\
\hline
\end{tabular}

Figure in parentheses indicate percentage

Source: Field Survey, 2018

\section{Reason behind lagging the idea of the pest}

Among the farmers who were unaware about the pest, (54.1\%) of farmers' main reason for lagging the idea of the pest was due to the lack of the government led extension activities followed by lack of technical knowhow $(35.7 \%)$ and lack of self-interest to know $(11.2 \%)$.

\begin{tabular}{|l|l|}
\hline \multicolumn{2}{|c|}{ Table 2. Respondents' response on reason behind lagging the idea of the pest } \\
\hline \multicolumn{1}{|c|}{ Reason } & \multicolumn{1}{|c|}{ Frequency } \\
\hline Lack of self interest to know & $11(11.2)$ \\
\hline Lack of technical knowhow & $34(35.7)$ \\
\hline Lack of Government led extension activities & $53(54.1)$ \\
\hline Total & $98(100)$ \\
\hline
\end{tabular}

Figure in parentheses indicate percentage

Source: Field Survey, 2018

\section{Farmers knowledge on the life cycle of Bactrocera minax}

Among 22 respondents having the knowledge about the pest, $63.3 \%$ did not know the life cycle of fruit fly, while
$36.3 \%$ of respondents did know the life cycle. Those respondents who knew the life cycle, they confidently answered mentioning the different stage of life cycle of fruit flies (Table 3 ).

\begin{tabular}{|l|l|}
\hline \multicolumn{2}{|c|}{ Table 3. Farmers' knowledge on the life cycle of Bactrocera minax (Enderlein) in the study area } \\
\hline \multicolumn{1}{|c|}{ Reason } & \multicolumn{1}{c|}{ Frequency } \\
\hline Yes & $8(36.3)$ \\
\hline No & $14(63.7)$ \\
\hline Total & $22(100)$ \\
\hline
\end{tabular}

Figure in parentheses indicate percentage

Source: Field Survey, 2018

\section{Extent of fruit drop duet to Bactrocera minax}

In most of the orchard, fruit drop ranged between 25 to $50 \%$. About $40 \%$ of orchard faced $25-50 \%$ fruit drop while $26.7 \%$ orchard faced $0-25$ percent fruit drop and $23 \%$ orchard faced $50-70 \%$ fruit drop and $8.3 \%$ orchard faced more than $75 \%$ fruit drop in year 2018. (Figure 2)

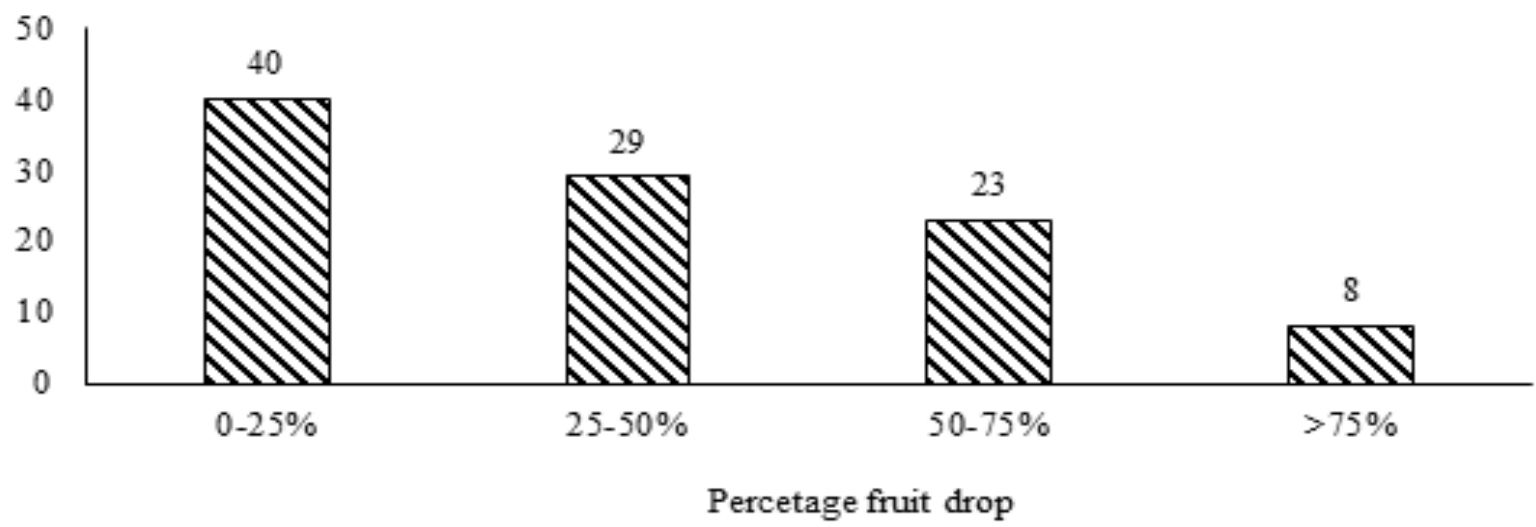

Figure 2: Extent of fruit drop due to Bactrocera minax infestation on Sindhuli, 2018 


\section{Different practices adopted to manage the fallen fruits}

The study revealed that the farmers managed the fallen fruits by different ways. Among the respondent $62.5 \%$ of the farmers dumped the fallen fruits in the pit, 52.5 percent farmers kept the fruits in the plastic bag, $44.2 \%$ farmers fed the fallen fruits to the livestock and $36.7 \%$ farmers mixed the fallen fruits into the manure pit. (Multiple responses were recorded)

\begin{tabular}{|l|l|l|l|l|}
\hline \multicolumn{5}{|c|}{ Table 4. Farmers' response on different practices adopted to manage the fallen fruits } \\
\hline Response & $\begin{array}{c}\text { Kept in plastic } \\
\text { bag }\end{array}$ & $\begin{array}{c}\text { Dumped in the } \\
\text { pit }\end{array}$ & $\begin{array}{c}\text { Mixed in manure } \\
\text { pit }\end{array}$ & $\begin{array}{c}\text { Fed to } \\
\text { livestock }\end{array}$ \\
\hline Yes & $63(52.5)$ & $75(62.5)$ & $44(36.7)$ & $53(44.2)$ \\
\hline No & $57(47.5)$ & $45(37.5)$ & $76(63.3)$ & $67(55.8)$ \\
\hline
\end{tabular}

Figure in parentheses indicate percentage

Source: Field Survey, 2018

\section{Management practices adopted by farmers for fruit fly control}

Among the different practices for management of fruit fly, $86.7 \%$ practiced collection and destruction of fallen fruits, $49.2 \%$ farmers used chemical pesticide, $38.3 \%$ farmers used traps as a management technique. Multiple responses were recorded.

\begin{tabular}{|l|l|l|l|}
\hline \multicolumn{4}{|c|}{ Table 5. Farmer's practice on fruit fly management in sweet orange in the survey area } \\
\hline Response of respondent & \multicolumn{1}{|c|}{ Chemical pesticide } & \multicolumn{1}{c|}{ Orchard sanitation } & \multicolumn{1}{c|}{ Use of trap } \\
\hline Yes & $59(49.2)$ & $104(86.7)$ & $46(38.3)$ \\
\hline No & $61(50.8)$ & $16(13.3)$ & $74(61.7)$ \\
\hline
\end{tabular}

Figure in parentheses indicate percentage

Source: Field Survey, 2018

\section{Farmers' knowledge on use of protein bait for the management of Bactrocera minax (Enderlein)}

The study revealed that only $18.3 \%$ of the farmers were aware about the use of protein hydrolysate to control Bactrocera minax

Table 6. Farmers' knowledge on use of protein bait for the management of Bactrocera minax (Enderlein)

\begin{tabular}{|l|l|}
\hline \multicolumn{1}{|c|}{ Response } & \multicolumn{1}{c|}{ Frequency } \\
\hline Yes & $22(18.3)$ \\
\hline No & $98(81.7)$ \\
\hline Total & $120(100)$ \\
\hline
\end{tabular}

Figure in parentheses indicate percentage

Source: Field Survey, 2018

\section{Farmers response on reasons behind increasing chinese fruit flies infestataion in sweet orange}

Among 120 respondent, most of the respondent expressed similar experiences. Following are the some reasons behind the increasing fruit flies infestation:

- Poorly understood insect biology as the farmers still have wrong perception that this pest can be controlled by using methyl eugenol and cue lure.

- Poor orchard sanitation

- No availability of appropriate chemical pesticides to control the pest..

- Lack of awareness on the use of protein bait in the study area.

- Inadequate supports receiving from the service providers. 
- Some respondents said that it might be due to the development of resistance power of fruit flies against the insecticides.

\section{Monitoring}

The population dynamics of Bactrocera minax (Enderlein) at different altitude were recorded during monitoring in selected field of sweet orange. Data pertaining to the occurrence of Chinese citrus fly at different altitude during the study period from May to June is presented in the Figure 4.

In the trap baited with protein hydrolysate installed at 1200 meters above the sea level, number of Bactrocera minax was the highest in 19th May i.e. total of six catches and the catches started decreasing after the onset of June (Figure 3).

In the trap baited with protein hydrolysate installed at 1300 meters above the sea level, number of Bactrocera minax was the highest on 26th May i.e. total of four catches and it started decreasing after the mid of June (Figure 3).

In the trap baited with protein hydrolysate at 1400 meters above the sea level. Bactrocera minax (Enderlein) was not seen during the month of the April and seen after the onset of May. The catches increased reaching the highest number in 2th June started decreasing by the end of the June (Figure 3)

Similar result was obtained by Dorji, et al. (2006) in which fully matured females first appeared in traps in mid to late May and reached the peak in mid to late June. Zhang (1989) stated that decrease in the population of B. minax during July was seen which might be due to single generation a year of Bactrocera minax. The adult flies of Bactrocera minax(Enderlein) emerging from overwintering pupal stage in late April to early May, maturing by the end of May and mating, which concludes that the abundance of Bactrocera minax is during the month of April/May. From the beginning of June males rapidly disappeared from the population and by mid to late June are rare or absent in trap (Dorji et al., 2006).

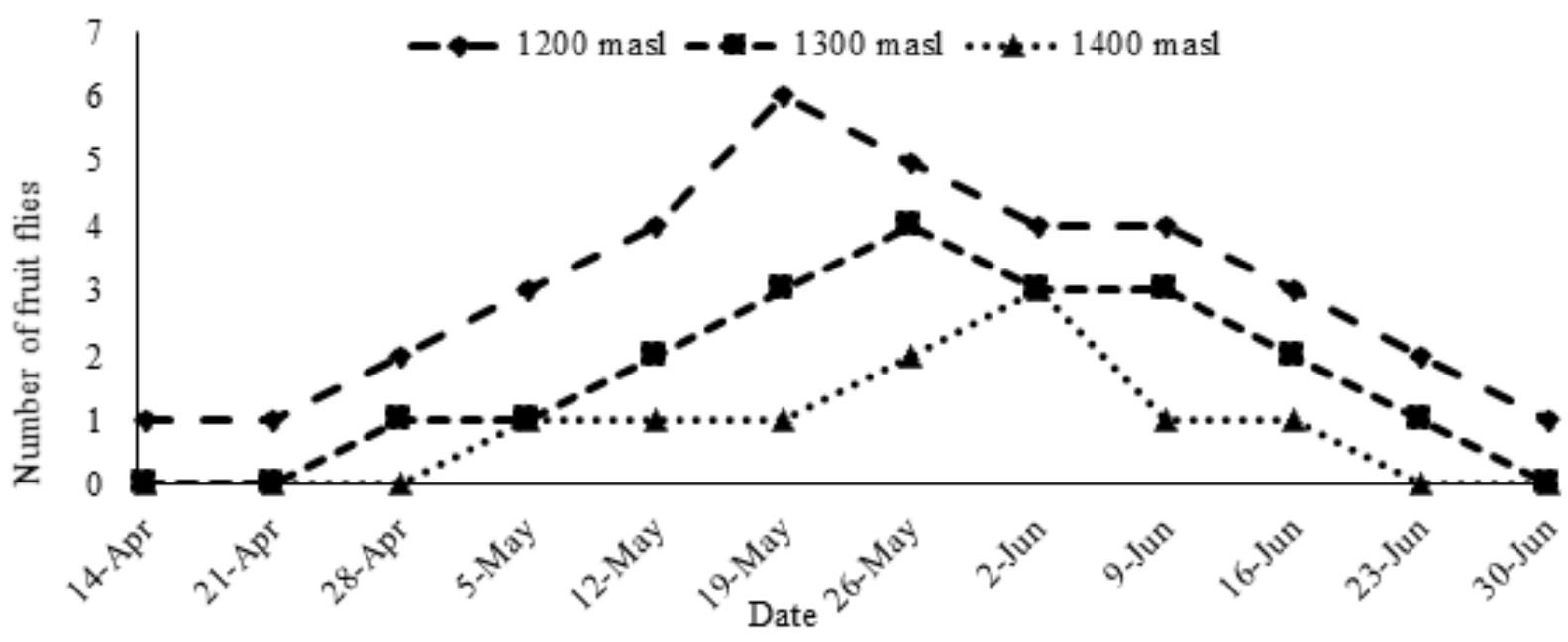

Figure 3: Number of fruit flies trapped in protein bait in the study area

Study revealed that the total fruit fly count was highest in 1200 masl followed by 1300 masl and 1400 masl (Figure 4).Number of fruit flies trapped in protein bait at 1200 masl is higher because of emergence of Chinese citrus fly first at 1200 masl followed by 1300 masl and 1400 masl. The temperature at 1200 masl was comparatively higher than 1300 masl and 1400 masl which is the indication for the early emergence of the fruit fly at lower altitude.
These findings are in agreement with that of Kounatidis, et al. (2008) where the population phenology seemed to affect spatial pattern and the amount of captured Bactrocera spp were higher at lower elevation. Similar result was obtained by Israely, Zin, \& Galun (2005) where they studied the temporal population at three altitude $(400 \mathrm{~m}, 400-600 \mathrm{~m},>600 \mathrm{~m})$ and more population of Bactrocera spp was observed in traps set 


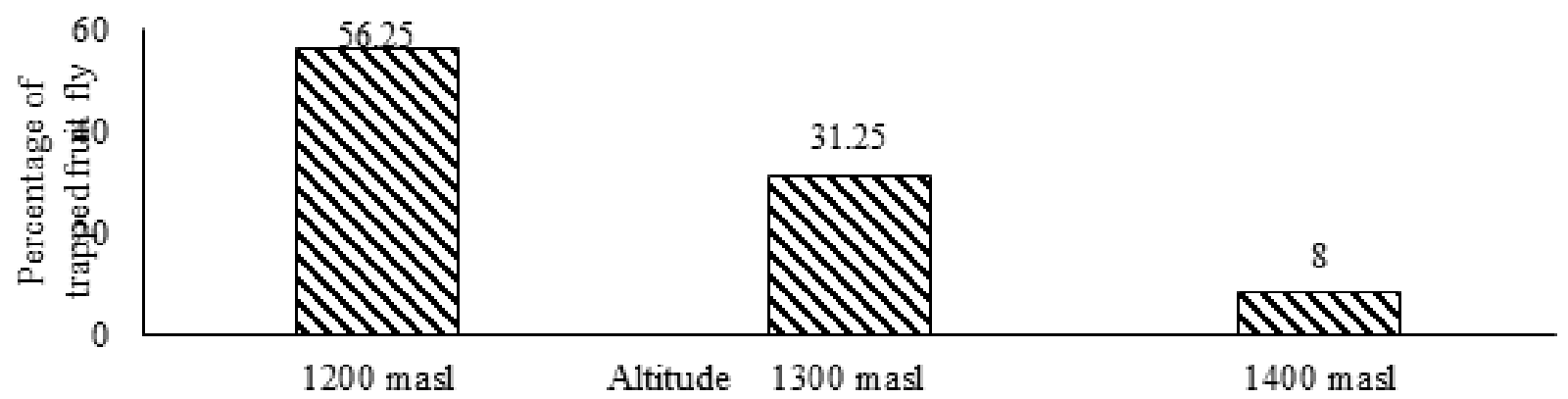

at lowest altitude and least population at highest altitude.

Figure 4: Population dynamics of Bactrocera minax (Enderlein) at different altitude in the study area

Study revealed that the adult emerged from the pupal stage at the end of the April and to the onset of the May (Figure 5). The fruit fly population reached the peak by the end of the May and the onset of the June and the population gradually decreased there after (Figure 3 ).

National Citrus Research Program (NCRP) also revealed that the adult flies emerged in the second half of April. The detailed study on: (i) adult emergence period; (ii) adult phenology patterns; (iii) period of

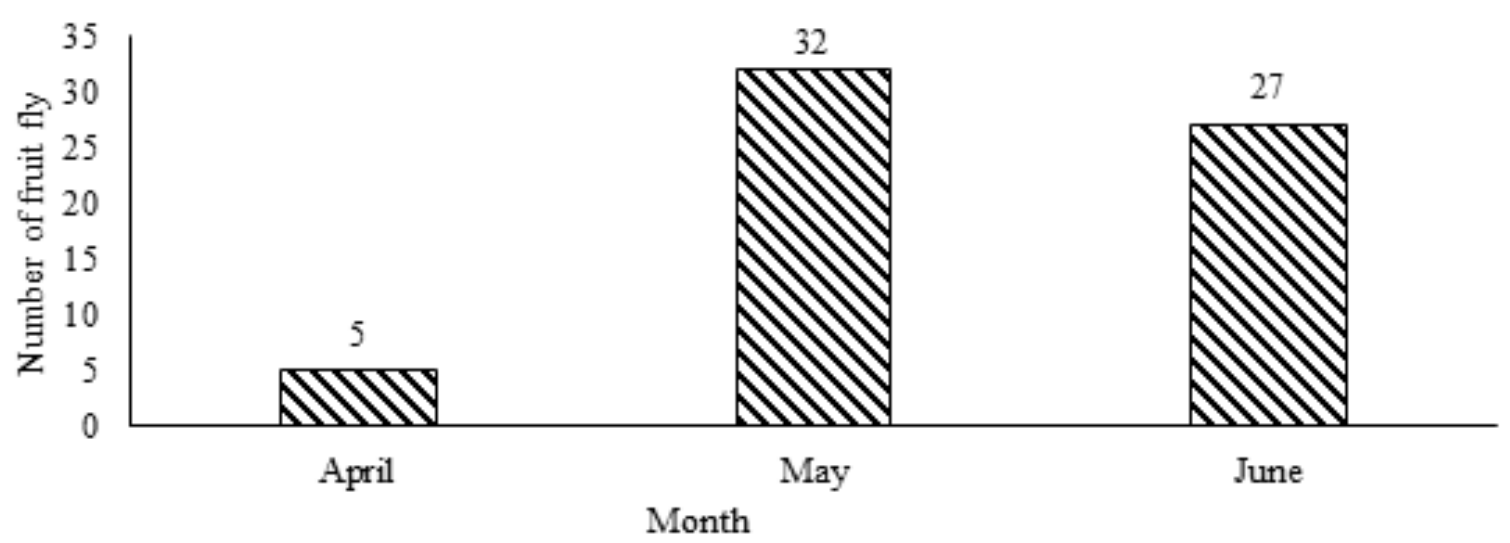

crop susceptibility; (iv) period from fruit drop to pupation and (v) developing of controlling measures is yet to be

carried out in Nepal (FAO, 2011).

Figure 5: Population dynamics of Bactrocera minax (Enderlein) in different months in the study area

\section{Conclusion}

Farmer's survey indicated that the farmers had poor knowledge regarding Bactrocera minax and its proper management practices. Respondents of study area demonstrated fair knowledge of the damage of Bactrocera minax but lacked knowledge of taxonomy and life cycle. Poor orchard management, poor effectiveness of the pesticides, lack of awareness on using protein bait to control Bactrocera minax were the major reasons of increasing fruit fly infestation. Protein hydrolysate lure was found effective for monitoring of Bactrocera minax. Total fruit fly count was found higher in 1200 masl followed by 1300 and 1400 masl. Bactrocera minax had peak emergence at May and the population gradually decreased on the onset of June. Thus, fruit fly management should be initiated before June for Bactrocera minax due to higher pest intensity recorded during this period. Based on this study, it is suggested that effective management practices should be adopted during the peak emergence period so as to reduce the loss caused by fruit fly. Integrated pest management should be followed with respect to life cycle of the fly. Protein hydrolysate either baits station or spot spray should be done during the peak emergence of adult flies for its proper management.

\section{Acknowledgement}


The authors are thankful to respondent farmers, Agriculture and Forestry University, Chitwan, Prime Minister Agriculture Modernization Project (PMAMP) for their support on performing this study.

\section{References}

Adhikari, D., \& Joshi, S. L. (2018). An Issue of Sweet Orange Fruit Fly in Sindhuli, Nepal: Possible Management Measures. Workshop on Chinese Citrus Fly (Bactrocera minax). Sindhuli, Nepal.

Adhikari, D., Baidhya, S., \& Koirala, D. . (2012). Citrus greening test on Sweet orange ( Junar ) by scratch method at Sindhuli district ,. Journal of Plant Protection Society, 4(January 2012), 263-268.

Adhikari, D., Thapa, R. B., Samudra, L., Joshi, X. H., Liang, J., Jinping, D., Adhikari, D., Thapa, R. B., Joshi, S. L., Liang, X. H., \& Du, J. J. (2020). Area-Wide Control Program of Chinese Citrus Fly Bactrocera minax (Enderlein) in Sindhuli, Nepal. American Journal of Agricultural and Biological Sciences Original Research Paper. https://doi.org/10.3844/ajabssp.2020.1.7

Dorji, C., Clarke, A. R., Drew, R. A. I., Fletcher, B. S., Loday, P., Mahat, K., Raghu, S., \& Romig, M. C. (2006). Seasonal phenology of Bactrocera minax (Diptera: Tephritidae) in western Bhutan. Bulletin of Entomological Research, 96(5), 531538. https://doi.org/10.1079/BER2006455

FAO. (2011). Training manual for combating citrus decline problem in Nepal. http://www.fao.org/ documents/card/en/c/556f7781-50ac-44ada51c-b0f0f36c6b49/

Adhikari, D., Dougound, J., Janner, W., \& Schaffner, U. (2016). Assessment of Performance of Plant Clinic in Nepal (A case of fruit fly management). MAS ICM thesis, Université de Neuchâte, Switzerland.

Agarwal, M., \& Sueyoshi, M. 2.-4. (2005). Catalogue of Indian fruit flies (Diptera: Tephritidae) Oriental Insect.

DADO. (2010). Annual Report.District Agriculture Deveopment Office. Sindhuli.

DADO. (2016). Annual Junar laboratory Activities 2015/2016. Sindhuli.

Dorji, C., Clarke, A. R., Drew, R. A. I., Fletcher, B. S.,
Loday, P., Mahat, K., Raghu, S., \& Romig, M. C. (2006). Seasonal phenology of Bactrocera minax (Diptera: Tephritidae) in western Bhutan. Bulletin of Entomological Research, 96(5), 531538. https://doi.org/10.1079/BER2006455

FAO. (2011). Training manual for combating citrus decline problem in Nepal. http://www.fao.org/ documents/card/en/c/556f7781-50ac-44ada51c-b0f0f36c6b49/

Israely, N., Zin, Y., \& Galun, R. (2005). Metapopulation Spatial-Temporal Distribution Patterns of Mediterranean Fruit Fly( Diptera:Tephritidae) in a patchy environment. Annals of the Entomological Society of America, 98(3), 302-308. Retrieved from https://doi. org/10.1603/0013-8746(2005)098[0302:MSDP $\mathrm{OM}] 2.0 . \mathrm{CO} ; 2$

Kaini, B. R. (2013). Package of Practices for Junar Production and post harvest management . JICA and JCCU.

Kounatidis, I., Papadopoulos, N., Mavragani-Tsipidou, P., Cohen, Y., Tertivanidis, K., Nomikou, N., \& Nestel, D. (2008, December). Effect of elevation on spatio-temporal patterns of olive fly(Bactrocera oleae)populations in northern Greece. Journal of Applied Entomology, 132(910), 722-733.

NCRP. (2006). Annual Report. Paripatle,Dhankuta: National Citrus Research Program.

Poudel, K., \& Regmi, C. (2008). Disease and insect pest of Citrus (A booklet in Nepali version). Nepal Agriculture Research council. Horticulture Research Station. Khumaltar, Lalitpur.

Sharma, D., Adhikari, D., \& Tiwari, D. (2015). Fruit Fly Surveillance in Nepal. Agricultural and Biological Sciences Journal, 1(3), 121-125.

Zhang, Y. (1989). Citrus fruit fliesof Sichuan Province (China). Bulletin OEPP/EPPO Bulletin, 19, 649654. 